\title{
Comportement et rôle des streptocoques lactiques du levain en fabrication de Camembert*
}

\author{
par \\ F. G. MARTLEY*** \\ Station Centrale de Recherches Laitières, I.N.R.A. \\ 78350 Jouy-en-Josas (France)
}

\section{Rés u mé}

Des cultures pures de Streptococcus cremoris AM 2 et de Str. lactis ML 8 ont été utilisées en fabrication expérimentale de Camembert. Des populations maximales de streptocoques lactiques égales ou supérieures à $10^{10}$ germes par g de matière sèche ont été obtenues dans le caillé au cours de la fabrication, lorsque la souche AM 2 ou la souche ML 8 étaient ensemencées dans le lait à $32^{\circ} \mathrm{C}$, ou lorsque la souche ML 8 était ensemencée dans le lait à $37^{\circ} \mathrm{C}$. Les fromages obtenus étaient de qualité organoleptique médiocre, présentant une amertume très marquée. Une réduction d'environ 10 fois de la population maximale des streptocoques était obtenue en ensemençant la souche AM 2 (souche relativement thermo-sensible) dans du lait à $37^{\circ} \mathrm{C}$, ou en contaminant à dessein le levain avec un bactériophage homologue. Cela déterminait une réduction marquée ou même la disparition complète de l'amertume et une amélioration notable de la qualité organoleptique des fromages.

Ces résultats corroborent l'hypothèse de Lowrie et Lawrence (1972), relative au rôle du levain dans la formation de l'amertume dans le fromage. Il semble toutefois que l'influence de la présure sur l'intensité de l'amertume soit moins importante dans le cas du Camembert que dans le cas du Cheddar. L'activité protéolytique de la moisissure superficielle du Camembert pourrait jouer le rôle le plus important dans la formation de précurseurs non amers, que les protéinases des streptocoques lactiques dégraderaient ensuite en peptides amers.

Une meilleure maîtrise de la fabrication du Camembert par la sélection des souches du levain lactique et par la modification des conditions de fabrication est discutée brièvement.

\footnotetext{
* Ce travail a été réalisé dans le cadre d'une action thématique programmée de l'Institut National de la Recherche Agronomique ( $\mathrm{n}^{\circ}$ 18766).

** Adresse actuelle : New-Zealand Dairy Research Institute, Private Bag, Palmerston North (New-Zealand).
} 


\section{INTRODUCTION}

Il est généralement admis que la moisissure (Penicillium) qui se développe à la surface du Camembert et des fromages similaires au cours de l'affinage, joue un rôle plus important que les autres microorganismes du fromage dans la maturation de la pâte et la formation du goût (Mocquot, 1955 ; Lenoir, 1970). Alors qu'il existe de nombreux travaux consacrés aux différentes souches de moisissures et à leurs activités enzymatiques (par exemple Lenoir et Choisy, 1971 ; Lambert et Lenoir, 1972), on considère généralement que les streptocoques lactiques mésophiles du levain n'ont pas d'autre rôle que la production d'acide au cours de la fabrication proprement dite du Camembert (Knoop et Peters, 1971).

Cependant, récemment, il a été clairement démontré que les streptocoques lactiques du levain exercent un rôle déterminant dans la formation de la flaveur du Cheddar. On obtient des fromages de Cheddar de bonne qualité organoleptique lorsqu'on utilise comme levains des cultures pures de streptocoques qui sont incapables d'atteindre des populations maximales élevées dans le caillé, au cours de la fabrication. Par contre, en employant des levains qui atteignent des populations maximales élevées dans le caillé on obtient des fromages présentant des défauts de goût, tels que l'amertume ou le goût fruité (Lawrence, Creamer, Gilles et Martley 1972 ; Martley et Lawrence, 1972 ; Lowrie, Lawrence, Pearce et Richards, 1972).

Le présent travail est consacré à l'étude du comportement, en fabrication de Camembert, de deux souches pures de streptocoques lactiques mésophiles utilisées comme levains. Ce travail montre que les streptocoques lactiques exercent une influence plus déterminante qu'il avait été précédemment admis, dans la formation du goût et l'apparition des défauts de goût de ce type de fromage.

\section{METHODES}

\section{Levains}

Au cours de ce travail, nous avons utilisé les souches Streptococcus cremoris AM 2 et Str. Lactis ML 8, souches provenant de la collection de cultures du New-Zealand Dairy Research Institute. Le lait utilisé pour préparer le levain était du lait reconstitué à partir de lait écrémé sec granulé (Elle-et-Vire), à raison de $10 \mathrm{~g}$ dans $100 \mathrm{ml}$ d'eau distillée. Ce lait était chauffé à $100^{\circ} \mathrm{C}$ pendant $30 \mathrm{mn}$, refroidi, ensemencé avec la souche choisie et la culture était incubée à $21^{\circ} \mathrm{C}$ pendant la nuit, de façon à obtenir le lendemain un levain présentant un $\mathrm{pH}$ situé entre 4,6 et 4,7. Dans cette zone de $\mathrm{pH}$, le levain présente 
une activité acidifiante maximale lorsqu'il est ensemencé dans le lait de fabrication (Pearce, Brice et Crawford, 1973).

\section{Fabrication}

Dans chaque essai, on fabriquait, à partir du même lait, deux ou trois lots de fromages, à raison d'une bassine de 1001 par lot. L'un des lots constituait chaque fois une fabrication témoin. Le lait, provenant d'un troupeau de l'I.N.R.A., était standardisé à un taux de matière grasse de $30 \mathrm{~g}$ par litre et pasteurisé à $72^{\circ} \mathrm{C}$ pendant $16 \mathrm{~s}$. Le nombre de germes présents dans le lait pasteurisé était toujours inférieur à $5.10^{4}$ par ml. Après pasteurisation le lait était refroidi à $32^{\circ} \mathrm{C}$ ou à $37^{\circ} \mathrm{C}$, suivant les essais, et ensemencé avec 2 p. 100 de levain.

Des essais préliminaires ayant montré qu'il n'était pas nécessaire de procéder à une maturation du lait ensemencé avant l'emprésurage, le lait était emprésuré immédiatement après l'addition du levain, en ajoutant $20 \mathrm{ml}$ de présure commerciale liquide (Hansen-Boll - 91290 Arpajon) à $100 \mathrm{~kg}$ de lait. Le coagulum était découpé et moulé lorsque son $\mathrm{pH}$ atteignait 6,2 et les moules étaient retournés toutes les $2 \mathrm{~h}$ pour faciliter l'égouttage. L'égouttage se poursuivait pendant la nuit. La température du lait de la bassine, $32^{\circ} \mathrm{C}$ ou $37^{\circ} \mathrm{C}$ suivant les cas, était maintenue constante jusqu'au moulage. Elle diminuait ensuite régulièrement, atteignant $27^{\circ} \mathrm{C} 3 \mathrm{~h}$ après le moulage et la température ambiante $\left(23^{\circ} \mathrm{C}\right) 6 \mathrm{~h}$ après le moulage.

Le lendemain matin, les fromages étaient démoulés et salés dans une saumure saturée pendant $30 \mathrm{~min}$. Ils étaient ensuite ensemencés en surface par pulvérisation d'une suspension de spores de Penicillium candidum (Laboratoires G. Roger - 77260 La Ferté-sous-Jouarre) et placés dans une salle d'affinage $\left(12^{\circ} \mathrm{C}\right.$, humidité relative $\left.90 \mathrm{p}, 100\right)$ afin d'obtenir un bon développement de la moisissure. 8 j plus tard les fromages étaient enveloppés dans leur papier d'emballage. Après 3 semaines d'affinage, les fromages étaient placés à $4^{\circ} \mathrm{C}$.

\section{Echantillonnage}

Des échantillons étaient prélevés sur le lait de fabrication immédiatement après addition du levain, sur le caillé au cours de l'égouttage et sur les fromages au cours des premiers jours d'affinage.

Les échantillons de fromage étaient constitués par des secteurs d'environ $50 \mathrm{~g}$. Ils étaient refroidis à une température inférieure à $10^{\circ} \mathrm{C}$ et soigneusement homogénéisés à l'aide d'une spatule, en observant les précautions usuelles d'asepsie tout au long de cette opération. Les échantillons ainsi préparés étaient utilisés pour effectuer les dénombrements, et pour déterminer la teneur en substance sèche, le taux de $\mathrm{NaCl}$ et le $\mathrm{pH}$. 


\section{Dénombrements}

Les bactéries lactiques étaient dénombrées sur le milieu gélosé M 16 (Lowrie et Pearce, 1971).

Pour le lait et le caillé, on effectuait les dilutions décimales dans de l'eau peptonée à 0,1 p. 100 refroidie à environ $5^{\circ} \mathrm{C}$. La première dilution était agitée pendant $30 \mathrm{~s}$ à l'aide d'un appareil Ultra-Turrax, de façon à réduire les chaînes de streptocoques à des longueurs comparables (Martley, 1972).

Dans le cas des échantillons de fromage, la première dilution était faite dans une solution de citrate de sodium à 2 p. 100 de façon à faciliter la dissolution. Les dilutions décimales ultérieures étaient faites comme précédemment dans de l'eau peptonée.

Les boîtes de Petri étaient incubées à $30^{\circ} \mathrm{C}$ pendant $48 \mathrm{~h}$. Cette incubation ne permet pas à la moisissure, qui commence à se développer à la surface des fromages âgés de 3 à $5 \mathrm{j}$, de former des colonies à la surface du milieu gélosé.

\section{Déterminations de la teneur en substance sèche et de la teneur en $\mathrm{NaCl}$}

Les teneurs en substance sèche des échantillons de lait, de caillé et de fromage étaient déterminées par dessiccation à l'étuve à $100^{\circ} \mathrm{C}-102^{\circ} \mathrm{C}$. La teneur en $\mathrm{NaCl}$ des fromages âgés de $5 \mathrm{j}$ était déterminée selon la méthode standard modifiée par Silverman, Wolin et Kosikowski (1959).

\section{Examen organoleptique}

Après 3 semaines d'affinage, les fromages étaient soumis à un examen organoleptique effectué par un jury composé de 5 à 8 personnes.

\section{RESULTATS}

Pour comparer les dénombrements effectués aux différents stades de la fabrication du fromage, nous avons tenu compte de la variation de la teneur en eau des échantillons successifs (tab. 1), et tous les résultats sont exprimés en nombre de germes par g de matière sèche. La légère perte d'eau observée entre l'ensemencement du lait et le découpage du caillé résultait probablement d'une évaporation de l'eau.

L'emploi de bassines ouvertes entrainnait occasionnellement, comme on pouvait s'y attendre, une contamination du levain utilisé en fabrication par un phage homologue. Toutefois les épreuves de routine effectuées selon la méthode de Lowrie et Pearce (1971) sur 
les échantillons qui servaient aux dénombrements bactériens, ont montré que le nombre de particules de phages présentes dépassait rarement $10^{4}$ par $g$ de matière sèche, quel que soit le stade de la fabrication. Les essais où l'on a mis en évidence des nombres plus élevés de phages, n’ont pas été inclus dans nos résultats.

Les teneurs en eau et en $\mathrm{NaCl}$ des fromages fabriqués au cours de ces essais (tab. 1) étaient caractéristiques du Camembert français. Un pH compris entre 4,5 et 5,0 au démoulage peut être considéré comme normal selon Knoop et Peters (1971), mais il est généralement préférable d'obtenir, en pratique, un $\mathrm{pH}$ inférieur ou égal à 4,6 (Mocquot, communication personnelle). Bien qu'il existât de petites différences de $\mathrm{pH}$ entre les différents fromages au démoulage, les fromages AM 2 - $37^{\circ} \mathrm{C}$ étant en particulier moins acides (tab. 1), les $\mathrm{pH}$ après 2 à 3 semaines d'affinage ne différaient pas significativement d'un fromage à l'autre.

\section{Effet de la souche bactérienne et de la température}

\section{Fromages fabriqués avec Str. lactis ML 8}

Lorsque la souche ML 8 était ensemencée dans du lait à $32^{\circ} \mathrm{C}$ (fromages ML $8-32^{\circ} \mathrm{C}$ ), le développement des streptocoques et l'acidification après l'ensemencement du lait $\left(2,3 \times 10^{\circ}\right.$ germes/g de matière sèche, $\mathrm{pH}$ 6,7), étaient rapides (fig. 1). Le caillé était découpé et moulé à $\mathrm{pH} 6,2,2$ h 40 plus tard. La population bactérienne était pratiquement à son maximum lorsque le $\mathrm{pH}$ du caillé atteignait $5,1,4 \mathrm{~h} 35$ après l'ensemencement, et cette population n'augmentait ensuite que lentement pour atteindre le lendemain matin le maximum de $3,3.10^{10}$ germes par g de matière sèche, le $\mathrm{pH}$ du caillé étant de 4,4. Ensuite, après salage et au cours des premiers jours de l'affinage, on n'observait qu'une légère diminution du nombre de Str. lactis ML 8.

On obtenait des résultats pratiquement identiques en ensemençant la même quantité de levain ML 8 dans du lait à $37^{\circ} \mathrm{C}$, au lieu de $32^{\circ} \mathrm{C}$ (fromages ML $8-37^{\circ} \mathrm{C}$ ). L'acidification était légèrement p.us rapide au début de la fabrication (tab. 1), mais le $\mathrm{pH}$ était le même au démoulage $(4,4)$. Au début de l'affinage des fromages ML $8-37^{\circ} \mathrm{C}$, on n'observait également qu'une légère diminution du nombre de streptocoques qui passait d'un maximum de $3,2.10^{10}$ germes par g de matière sèche à $2,8.10^{10}$ après $5 \mathrm{j}$ d'affinage.

\section{Fromages fabriqués avec Str. cremoris AM 2}

Lorsque la souche AM 2 était ensemencée dans du lait à $32^{\circ} \mathrm{C}$ (fromages AM $2-32^{\circ} \mathrm{C}$ ) l'acidification s'effectuait plus lentement que dans le cas des deux séries de fromages obtenus avec ML 8 (tab. 1), mais le $\mathrm{pH}$ des fromages au démoulage, le lendemain matin, était le même. L'augmentation de la population de la souche AM 2 était comparable à celle qu'on observait dans les séries de fromages fabriqués avec la souche ML 8. La population maximale était atteinte 


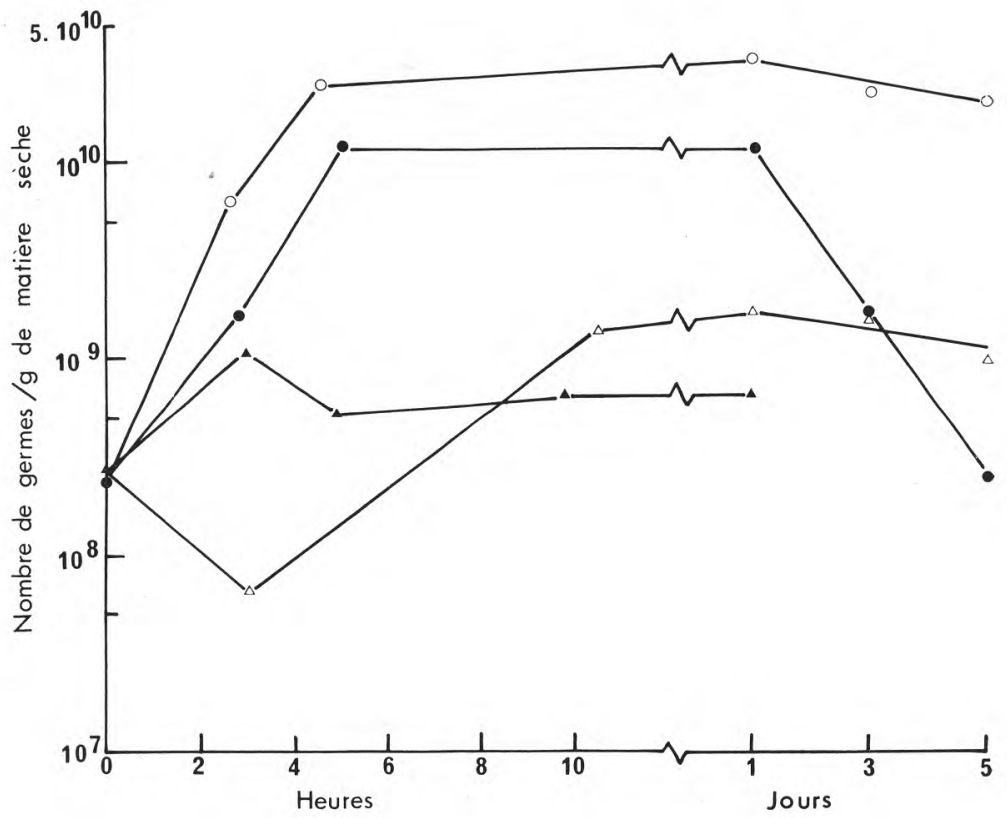

fig. 1

Evolution du nombre de streptocoques lactiques en fabrication expérimentale de Camembert. Le lait était ensemencé à raison de 2 p. 100 avec la culture pure étudiée et emprésuré au temps zéro.

- Streptococcus lactis ML 8 ensemencé dans du lait à $32^{\circ} \mathrm{C}$;

- Str. cremoris AM 2 ensemencé dans du lait à $32^{\circ} \mathrm{C}$;

$\triangle$ Str. cremoris AM 2 ensemencé dans du lait à $37^{\circ} \mathrm{C}$;

- Str. cremoris AM 2 ensemencé dans du lait à $32^{\circ} \mathrm{C}$, et addition parallèle de $1,2 \times 10^{4}$ particules de phage am 2 par $\mathrm{g}$ de matière sèche.

Les autres détails relatifs à la fabrication figurent dans le texte. Les dénombrements ont été exprimés en nombre de germes par $\mathrm{g}$ de matière sèche, afin de tenir compte de l'évolution de la teneur en matière sèche aux différentes étapes de la fabrication (voir aussi le tableau 1). 
Données analytiques des fabrications expérimentales de Camembert : teneur en matière sèche des échantillons utilisés pour dénombrer les streptocoques lactiques, évolution du pH pendant la fabrication et teneur en sel

\begin{tabular}{|c|c|c|c|c|c|c|c|c|c|}
\hline \multirow{2}{*}{$\begin{array}{l}\text { Souche utilisée } \\
\text { et température } \\
\text { du lait } \\
\text { à l'ensemencement }\end{array}$} & \multirow{2}{*}{$\begin{array}{l}\text { Nombre } \\
\text { d'essais }\end{array}$} & \multicolumn{2}{|c|}{ Matière sèche } & \multirow{2}{*}{$\begin{array}{c}\text { Temps } \\
\text { séparant } \\
\text { l'ensemen- } \\
\text { cement du } \\
\text { découpage } \\
\text { h, mn }\end{array}$} & \multirow{2}{*}{$\begin{array}{l}\text { Matière } \\
\text { sèche } \\
\text { du caillé à } \\
\text { pH 5,2-5,1 } \\
\text { p. } 100\end{array}$} & \multirow{2}{*}{$\begin{array}{c}\text { Temps } \\
\text { nécessaire } \\
\text { pour } \\
\text { atteindre } \\
\text { un pH de } \\
5,2-5,1 \\
\text { h, mn }\end{array}$} & \multirow{2}{*}{$\begin{array}{l}\text { Matière } \\
\text { sèche } \\
\text { au } \\
\text { démoulage } \\
\text { p. } 100\end{array}$} & \multirow{2}{*}{$\begin{array}{c}\mathrm{pH} \\
\mathrm{au} \\
\text { démoulage }\end{array}$} & \multirow{2}{*}{$\begin{array}{l}\mathrm{NaCl} \\
\text { à } 5 \mathrm{j} \\
\text { p. } 100\end{array}$} \\
\hline & & $\begin{array}{l}\text { à l'ense- } \\
\text { mencement } \\
\text { p. } 100\end{array}$ & $\begin{array}{l}\text { au } \\
\text { découpage } \\
\text { p. } 100\end{array}$ & & & & & & \\
\hline ML $832^{\circ} \mathrm{C}$ & 3 & & & 2,38 & 26,6 & 4,55 & 40,1 & 4,4 & 1,4 \\
\hline ML $837^{\circ} \mathrm{C}$ & 2 & & & 2,20 & 29,3 & 4,10 & 41,3 & 4,5 & 1,4 \\
\hline AM $232^{\circ} \mathrm{C}$ & 9 & 11,3 & 12,1 & 2,48 & 24,7 & 5,02 & 40,3 & 4,4 & 1,3 \\
\hline AM $237^{\circ} \mathrm{C}$ & 3 & & & 3,04 & 32,9 & 10,29 & 40,2 & 5,0 & 1,5 \\
\hline $\begin{array}{l}\mathrm{AM} 232^{\circ} \mathrm{C} \\
+ \text { phage am } 2\end{array}$ & 2 & & & 2,58 & 26,5 & 5,01 & 40,5 & 4,8 & 1,5 \\
\hline
\end{tabular}

Les fromages étaient faits en bassines de $100 \mathrm{l}$. Le lait était ensemencé avec $2 \mathrm{p} .100$ de levain et on procédait immédiatement à l'emprésurage $(20 \mathrm{ml}$ de présure $/ 100 \mathrm{~kg}$ de lait). Dans les deux dernières fabrications, on ajoutait au lait, en même temps que le levain AM 2, 1,3.10 particules du phage am 2/ml de lait. 
à $\mathrm{pH} 5,1$ et demeurait constante jusqu'au démoulage (fig. 1). Par contre, après salage, le nombre de cellules viables diminuait rapidement, observation qui s'explique par la sensibilité bien connue de cette souche au chlorure de sodium (Martley et Lawrence, 1972 ; Lowrie, Lawrence et Peberdy, 1974).

Lorsqu'on ensemençait AM 2 dans du lait à $37^{\circ} \mathrm{C}$ (fromages AM 2 $37^{\circ} \mathrm{C}$ ), le $\mathrm{pH}$ de 6,2 dans le coagulum était atteint $20 \mathrm{mn}$ plus tard que dans le cas de la fabrication témoin AM 2 effectuée à $32^{\circ} \mathrm{C}$ (tab. 1). Pendant cette période, le nombre de cellules viables de la souche AM 2 diminuait jusqu'à $6,3 \times 10^{7}$ germes par g de matière sèche (fig. 1). Ensuite, au cours de la phase d'égouttage pendant laquelle la température décroît, on observait une acidification lente jusqu'à $\mathrm{pH} 5,0$ au démoulage, le lendemain matin, acidification accompagnée par une lente augmentation du nombre de cellules viables de AM 2, qui atteignait un maximum de $1,8 \times 10^{\circ}$ germes par $\mathrm{g}$ de matière sèche. La lenteur de l'acidification entraînait un égouttage beaucoup plus lent que dans le cas des autres fabrications, mais les extraits secs de tous les fromages, au moment du démoulage, étaient comparables (tab. 1).

Après salage, le nombre de cellules viables de la souche AM 2 ne diminuait pas très rapidement, contrairement à ce qu'on observe normalement avec Str. cremoris. A ce point de vue, AM 2 se comportait dans ces conditions d'une façon analogue à la souche Str. lactis ML 8. Une modification similaire de la sensibilité au $\mathrm{NaCl}$, résultant du chauffage, a récemment été observée dans le cas de Streptococcus faecium (Duitschawer et Jordan, 1974).

\section{Qualité organoleptique}

La qualité organoleptique des trois premières séries de fromages, ML $8-32^{\circ} \mathrm{C}$, ML $8-37^{\circ} \mathrm{C}$ et AM $2-32^{\circ} \mathrm{C}$ était dans l'ensemble médiocre. Cela était dû principalement à une amertume très marquée, fréquemment notée comme particulièrement intense au voisinage de la surface du fromage.

Par contre, la flaveur des fromages AM 2 - $37^{\circ} \mathrm{C}$ était tout à fait acceptable et la qualité organoleptique des fromages de cette série était généralement considérée comme satisfaisante par la majorité du jury de dégustation. Il n'était pas fait mention du défaut d'amertume, sinon à un niveau très bas, ne dépassant guère le seuil limite de perception de ce défaut.

\section{Effet des phages}

Lowrie et al. (1974) ont montré qu'on pouvait obtenir expérimentalement une amélioration notable de la qualité organoleptique du 
Cheddar, en particulier une diminution de l'amertume, en procédant à une contamination contrôlée du levain par des phages homologues, au moment de l'ensemencement de la cuve de fabrication. L'acidification au cours de la fabrication n'était pas affectée de façon appréciable par cette contamination. Par contre, la multiplication des cellules était suffisamment affectée et il en résultait une réduction importante de la population maximale atteinte par le levain, dans le caillé.

Des essais similaires à ceux de Lowrie et al. (1974) ont été effectués, pour déterminer les effets d'une contamination par les phages en fabrication de Camembert. Les fromages étaient fabriqués comme il a été décrit précédemment, en ensemençant du lait à $32^{\circ} \mathrm{C}$ avec la souche AM 2, toutes conditions favorables normalement à l'obtention d'une population élevée de streptocoques dans le caillé égoutté et d'un fromage affiné présentant une flaveur médiocre. Le phage am 2, homologue de la souche AM 2 (provenant du New-Zealand Dairy Research Institute), était préparé dans les conditions définies par Lowrie et al. (1972) et ajouté au lait de fabrication, à différentes concentrations, en même temps que le levain AM 2.

L'addition d'un nombre de particules de phages ne dépassant pas $10^{2}$ par $\mathrm{ml}$ de lait était apparemment sans effet en fabrication, tandis qu'une contamination initiale égale ou supérieure à $5 \times 10^{3}$ particules par ml entraînait un arrêt de l'acidification au cours de la fabrication, arrêt consécutif à une lyse presque complète des cellules du levain AM 2 vérifiée par l'observation microscopique. Une contamination initiale du lait avec $1,3 \times 10^{3}$ particules par $\mathrm{ml}\left(1,2 \times 10^{4}\right.$ phages par g de matière sèche) permettait d'effectuer une fabrication apparemment normale. La population maximale de streptocoques $\left(10^{3}\right.$ germes par $\mathrm{g}$ de matière sèche) était obtenue au démoulage (fig. 1), le nombre de phages à ce moment atteignant $5 \times 10^{7}$ par $\mathrm{g}$ de matière sèche. $5 \mathrm{~h}$ après le début de la fabrication, lorsque le $\mathrm{pH}$ atteignait 5,1 , on observait une augmentation importante du nombre de phages qui était passé à $5 \times 10^{\circ}$ par $\mathrm{g}$ de matière sèche, alors que le nombre de streptocoques diminuait légèrement et n'était plus que de $5 \times 10^{8}$ germes par g de matière sèche.

L'effet de la contamination par les phages se traduisait par un $\mathrm{pH}$ légèrement plus élevé $(4,8)$ au démoulage que celui des fromages témoins $(4,4)$. L'extrait sec et la teneur en $\mathrm{NaCl}$ des fromages contenant des phages étaient comparables à l'extrait sec et à la teneur en $\mathrm{NaCl}$ des fromages témoins.

Dans les deux fabrications d'essai comportant une addition de phages, fabrications qui peuvent être considérées comme satisfaisantes tant du point de vue de la limitation de la population maximale de streptocoques que du point de vue de l'acidification, la flaveur des fromages obtenus était nettement supérieure à celle des fromages 
témoins correspondants, ne comportant pas d'addition de phages au levain.

\section{DISCUSSION}

Le présent travail a montré que des populations de streptocoques lactiques mésophiles de 1 à $3 \times 10^{10}$ germes par $\mathrm{g}$ de matière sèche sont atteintes dans des Camemberts fabriqués en ensemençant du lait à $32^{\circ} \mathrm{C}$ avec l'une ou l'autre des deux souches Str. cremoris AM 2 ou Str. lactis ML 8. Les populations atteintes par ML 8 ne diminuaient que lentement après salage et au cours des premiers jours de la période d'affinage du fromage, alors que les populations formées par AM 2 diminuaient rapidement. Cela corrobore les observations précédentes relatives à la plus ou moins grande sensibilité au sel des souches de Str. cremoris et de Str. lactis en général, et de ces deux souches en particulier (Dawson et Feagan, 1957 ; Martley et Lawrence, 1972). La flaveur de ces fromages était généralement médiocre, en raison d'une amertume prononcée jugée inacceptable. La méthode courante de fabrication du Camembert qui consiste à ensemencer le lait avec une quantité de levain ne dépassant pas 0,5 p. 100 et à lui faire subir une maturation pendant la nuit à température relativement basse conduit aussi à des populations élevées de streptocoques dans le caillé et à des fromages médiocres.

Suivant l'hypothèse formulée par Lowrie et Lawrence (1972) l'amertume du Cheddar est liée à la formation d'un " pool " de peptides amers obtenus principalement par l'action des protéinases du levain lactique sur les peptides de poids moléculaire élevé, non amers, résultant de l'action protéolytique de la présure. Les fromages de Cheddar étaient amers lorsque les conditions de fabrication étaient favorables au développement de populations de streptocoques lactiques supérieures à $4 \times 10^{\natural}$ germes par g de fromage (soit plus de $6 \times 10^{9}$ germes par $\mathrm{g}$ de matière sèche). Il était possible de réduire ou même d'éliminer l'amertume et ainsi obtenir des fromages nettement mieux notés sur le plan de la qualité organoleptique, soit en limitant la population maximale atteinte par les streptocoques à environ $10^{\circ}$ germes par $\mathrm{g}$ de matière sèche, soit en utilisant des quantités plus faibles de présure.

Les résultats présents obtenus en fabrication expérimentale de Camembert sont en bon accord avec cette hypothèse, qui associe d'une part la flaveur médiocre et l'amertume à l'existence de populations élevées de streptocoques lactiques dans le caillé, populations égales ou supérieures à $10^{10}$ germes par $\mathrm{g}$ de matière sèche, et d'autre part une bonne flaveur et l'absence d'amertume avec la présence de populations maximales plus faibles (c'est-à-dire voisines de $2 \times 10^{\circ}$ germes par $\mathrm{g}$ de matière sèche). Nous avons réussi à limiter la 
population de streptocoques soit en ensemençant la plus thermosensible des deux souches, AM 2, dans du lait à $37^{\circ} \mathrm{C}$, température supérieure à sa température optimale de croissance, soit en ajoutant délibérément des phages homologues de cette souche, à un taux suffisamment bas pour éviter de perturber gravement l'acidification.

Ces résultats confirment aussi les observations faites précédemment dans le cas du Cheddar, en ce qui concerne le manque de corrélation entre la survie des streptocoques et la flaveur du fromage. La population de streptocoques lactiques diminuait plus rapidement dans les fromages AM $2-32^{\circ} \mathrm{C}$ que dans les fromages ML 8 - $32^{\circ} \mathrm{C}$, mais les deux séries de fromages présentaient cependant une flaveur médiocre où dominait l'amertume.

Stadhouders (1974) a suggéré que la température à laquelle est porté le caillé au cours de la fabrication du Gouda détermine la quantité de présure retenue dans le fromage et, de cette façon, exerce une influence sur le développement de l'amertume dans le fromage. Cela ne semble pas s'appliquer au Camembert puisque les fromages ML 8, qu'ils aient été fabriqués à $32^{\circ} \mathrm{C}$ ou à $37^{\circ} \mathrm{C}$, étaient très amers dans les deux cas. Il est bien possible que le rôle joué par la présure dans l'apparition de l'amertume ne soit pas aussi déterminant dans le cas du Camembert que dans le cas du Gouda ou du Cheddar. Nous n'avons par exemple pas réussi, de façon convaincante, à diminuer l'amertume des fromages AM 2 - $32^{\circ} \mathrm{C}$ et ML 8 - $32^{\circ} \mathrm{C}$ dans des essais où nous avions réduit la quantité de présure employée à $12 \mathrm{ml}$ pour $100 \mathrm{~kg}$ de lait. De plus, nous n'avons pas obtenu une augmentation appréciable de l'amertume en employant une forte quantité de présure $(30 \mathrm{ml}$ pour $100 \mathrm{~kg}$ de lait). Ces échecs peuvent être attribués au fait que l'affinage du Camembert ( 3 semaines) est beaucoup plus court que celui du Cheddar (période d'affinage égale ou supérieure à 3 mois), ou au fait que la présence de quantités relativement importantes de protéinase fongique masque, dans le cas du Camembert, l'effet éventuel de la présure.

La moisissure superficielle du Camembert est responsable de la remontée du $\mathrm{pH}$ du fromage au cours de l'affinage, jusqu'à une valeur égale ou supérieure à 6,5 . Cette remontée du $\mathrm{pH}$ résulte à la fois de la consommation de l'acide lactique et de la protéolyse intense (Lenoir, 1970). Il semble peu probable que l'activité protéolytique de la moisissure soit, par elle-même, responsable de l'amertume du Camembert. En effet, les fromages AM 2 dans lesquels les populations de streptocoques étaient limitées soit par la température, soit par les phages, n'étaient pas amers. Ces fromages étaient comparables, en ce qui concerne les autres données analytiques, aux fromages amers AM $2-32^{\circ} \mathrm{C}$, au moment de la dégustation.

Il est possible que la protéinase fongique agisse, au cours de l'affinage du Camembert, d'une façon analogue à la présure dans 
le cas du Cheddar, en produisant des précurseurs non amers qui, sous l'action des protéinases des streptocoques lactiques, donnent naissance à des peptides amers. Mentionnons, pour appuyer cette hypothèse, que les membres du jury de dégustation ont fréquemment remarqué que l'amertume était plus intense au voisinage de la surface du fromage c'est-à-dire dans la zone où la concentration de la protéinase fongique est la plus élevée (Lenoir, 1970).

Le Camembert est un fromage moins salé et plus humide que le Cheddar, et ces caractéristiques peuvent également contribuer à un développement rapide d'une amertume intense dans le Camembert. De plus, il est possible que l'aptitude sensorielle permettant d'apprécier l'amertume soit favorisée par la dégustation d'un fromage neutre tel que le Camembert affiné.

La qualité organoleptique des Camemberts qu'on trouve dans le commerce peut varier de façon notable, et dans le passé, les défauts observés ont été fréquemment imputés au développement de divers micro-organismes indésirables (Pommerleau, 1973). Ce n'est que très récemment que l'amertume a été mentionnée, en France comme un défaut de goût sérieux et fréquent du Camembert et des fromages du même type (Pélissier, Mercier et Ribadeau-Dumas, 1974). L'emploi du lait pasteurisé s'étant généralisé dans la fabrication des fromages à pâte molle, les fromagers ne pouvaient plus compter sur la flore acidifiante du lait cru et ils ont été amenés à utiliser des levains lactiques. Nos résultats laissent à penser que cette évolution a certainement contribué, de façon déterminante, à accentuer les effets des streptocoques lactiques sur le développement de la flaveur du fromage. De ce point de vue, il apparaîtrait souhaitable d'éviter de fabriquer des fromages dans lesquels les streptocoques lactiques atteignent des nombres très élevés. Toutefois, dans la pratique fromagère, le nombre maximum de streptocoques présents dans le caillé et secondairement la qualité organoleptique des fromages affinés, peuvent varier d'un jour à l'autre dans de larges limites, suivant la sévérité des attaques de phages. Ces attaques sont en effet très répandues en fromagerie de pâte molle, encore qu'elles soient souvent méconnues (Accolas et Martley, observations non publiées).

L'industrialisation et la mécanisation de la fabrication des fromages à pâte molle connaissent actuellement un essor rapide. Cette évolution accentue la nécessité de disposer de procédés de fabrication plus rationnels et plus réguliers (Maubois et Mocquot, 1971). L'obtention d'un fromage présentant une bonne flaveur est tout autant souhaitable. Cela implique, nous l'avons montré, une sélection soigneuse des levains utilisés et une maîtrise du développement des streptocoques au cours de la fabrication du fromage. Nous y sommes parvenus expérimentalement en soumettant une souche particulièrement thermo-sensible à un "choc thermique " relativement long $(3 \mathrm{~h})$ à $37^{\circ} \mathrm{C}$. Le recours à des températures plus élevées appliquées 
pendant des temps plus courts serait peut-être préférable et mieux adapté à une application industrielle. L'étude de ce problème, portant sur différentes souches de streptocoques lactiques, est actuellement en cours.

\section{Remerciements}

L'auteur exprime sa vive reconnaissance à MM. Accolas, Auclair, Mocquot et Vassal pour leurs suggestions et leurs critiques, qui lui ont été très utiles tant dans la réalisation que dans la rédaction de ce travail. Il remercie très vivement MM. Nicolas et Vachot de leur précieuse collaboration, dans les essais de fabrication de Camembert.

\section{S u $\mathbf{m} \mathbf{m}$ a r y}

THE BEHAVIOUR AND ROLE OF STARTER STREPTOCOCCI

IN CAMEMBERT CHEESEMAKING

The single strain starter Streptococcus cremoris AM 2 and S. lactis ML 8 were used in experimental Camembert cheesemaking. Maximum starter populations of $\geqslant 10^{10}$ colony-forming-units/g of dry matter were obtained in the curd during cheesemaking when either strain AM 2 or strain ML 8 was inoculated into milk at $32^{\circ} \mathrm{C}$, or when strain ML 8 was inoculated into milk at $37^{\circ} \mathrm{C}$. The resultant cheeses were of poor flavour and intensely bitter. A reduction of ca 10 -fold in the maximum starter population was achieved by inoculating the more heat-sensitive strain AM 2 into milk at $37^{\circ} \mathrm{C}$, or by the deliberate infection of the starter with homologous phage. This resulted in a marked reduction or elimination of bitterness and a great improvement in the overall flavour acceptability of the cheeses.

The findings support the hypothesis of Lowrie \& Lawrence (1972) regarding the role of starter in the formation of bitterness in cheese. It is suggested however that the importance of rennet in influencing the intensity of bitterness may be less in the case of Camembert cheeses than in the case of Cheddar. The proteolytic activity of the surface mould flora of Camembert cheeses may play the more important role in providing the precursors, in themselves not bitter, which the starter proteinases degrade to bitter peptides.

Greater control of Camembert cheesemaking by selection of starter strains and adjustment of manufacturing conditions is briefly discussed. 


\section{Références}

Dawson (D. J.) and Feagan (J. T.) (1957). - J. Dairy Res., 24, 210.

Duitschaever (C. L.) and Jordan (D. C.) (1974). - J. Milk Fd Technol., 37, 382.

Knoop (A. M.) und Peters (K. H.) (1971). - Milchwissenschaft, 26, 193.

LAMBeret (G.) et LENoIr (J.) (1972). - Le Lait, 52, 175.

Lawrence (R. C.), Creamer (L. K.), Gilles (J.) and Martley (F. G.) (1972). N.Z. J. Dairy Sci. Technol., 7, 32.

LENOIR (J.) (1970). - Revue Lait. Fr., no 275, 231.

Lenoir (J.) et Choisy (C.) (1971). - Le Lait, 51, 138.

Lowrie (R. J.) and Lawrence (R. C.) (1972). - N.Z. J. Dairy Sci. Technol., 7, 51.

Lowrie (R. J.), Lawrence (R. C.) and Peberdy (M. F.) (1974). - N.Z. J. Dairy Sci. Technol., 9, 166.

Lowrie (R. J.), LaWrence (R. C.), Pearce (L. E.) and Richards (E. L.) (1972). N.Z J. Dairy Sci. Technol., 7, 44.

Lowrie (R. J.) and Pearce (L. E.) (1971). - N.Z. J. Dairy Sci. Technol., 6, 166.

MaRtley (F. G.) (1972). - N.Z. J. Dairy Sci. Technol., 7, 7.

Martley (F. G.) and Lawrence (R. C.) (1972). - N.Z. J. Dairy Sci. Technol., 7, 38.

Maubois (J. L.) et Mocouot (G.) (1971). - Le Lait, 51, 495.

Mocouot (G.) (1955). - J. Soc. Dairy Technol., 8, 17.

Pearce (L. E.), Brice (S. A.) and Crawford (A.M.) (1973). - N.Z J. Dairy Sci. Technol., 8, 41.

Pelissier (J. P.), Mercier (J. C.) et Ribadeau-Dumas (R.) (1974). - Revue Lait. Fr., $\mathrm{n}^{\circ} 325,1$.

Pommerleau (F.) (1973). - Le Lait, 53, 105.

Silverman (G. J.) and Kosikowski (F. V.) (1959). - J. Dairy Sci., 42, 1095.

STADHOUdERS (J.) (1974). - Milchwissenschaft, 29, 329. 